\title{
Effects of short light/dark cycles on photosynthetic pathway switching and growth of medicinal Dendrobium officinale in aeroponic cultivation
}

\author{
Yongsan Cheng ${ }^{1}$, Dongxian $\mathrm{He}^{1 *}$, Jie $\mathrm{He}^{2}$, Genhua $\mathrm{Niu}^{3}$, Fang $\mathrm{Ji}^{1}$ \\ (1. Key Lab. Agricultural Engineering in Structure and Environment, Ministry of Agriculture and Rural Affairs, China Agricultural \\ University, Beijing 100083, China; 2. National Institute of Education, Nanyang Technological University, Singapore 637616, Singapore; \\ 3. Texas AgriLife Research and Extension Center at Dallas, Texas A\&M University System, Dallas, TX 75252, USA)
}

\begin{abstract}
Dendrobium officinale has high medicinal value but grows slowly in natural environment due to its special CAM photosynthetic pathway. In this study, D. officinale were grown aeroponically with light/dark cycles of $12 \mathrm{~h} / 12 \mathrm{~h}, 4 \mathrm{~h} / 4 \mathrm{~h}$, and $2 \mathrm{~h} / 2 \mathrm{~h}$ for $150 \mathrm{~d}$. The photosynthetic electron transfer characteristics, photosynthetic $\mathrm{CO}_{2}$ fixation pathways, and accumulations of biomass and soluble polysaccharides in $D$. officinale leaves were studied. The results showed that the photosynthetic apparatus states of $D$. officinale in aeroponic cultivation under short light/dark cycles of $4 \mathrm{~h} / 4 \mathrm{~h}$ and $2 \mathrm{~h} / 2 \mathrm{~h}$ were better than that under $12 \mathrm{~h} / 12 \mathrm{~h}$. The dark net $\mathrm{CO}_{2}$ exchange percentages of $D$. officinale were negative in short light/dark cycles of $4 \mathrm{~h} / 4 \mathrm{~h}$ and $2 \mathrm{~h} / 2 \mathrm{~h}$, and the daily net $\mathrm{CO}_{2}$ exchange amount and dry/fresh weight increases were doubled compared with those in $12 \mathrm{~h} / 12 \mathrm{~h}$ light/dark cycle. High soluble polysaccharides content and the soluble polysaccharides yield of $D$. officinale were obtained in the shorter light/dark cycle of $2 \mathrm{~h} / 2 \mathrm{~h}$. Therefore, the photosynthetic pathway of $D$. officinale could be switched from CAM to $\mathrm{C} 3$ by short light/dark cycles of $4 \mathrm{~h} / 4 \mathrm{~h}$ and $2 \mathrm{~h} / 2 \mathrm{~h}$, and its higher biomass accumulation and soluble polysaccharides yield could be obtained by the shorter light/dark cycle of $2 \mathrm{~h} / 2 \mathrm{~h}$ in aeroponic cultivation.
\end{abstract}

Keywords: dark net $\mathrm{CO}_{2}$ exchange percentage, photosynthetic pathway, short light/dark cycle, soluble polysaccharides DOI: $10.25165 /$ j.ijabe.20191205.4864

Citation: Cheng Y S, He D X, He J, Niu G H, Ji F. Effects of short light/dark cycles on photosynthetic pathway switching and growth of medicinal Dendrobium officinale in aeroponic cultivation. Int J Agric \& Biol Eng, 2019; 12(5): 38-43.

\section{Introduction}

Dendrobium officinale, an Orchidaceae, has high medicinal value. However it grows very slowly in natural environment. It takes 3-5 years to harvest under artificial cultivation environment. This may be due to its special photosynthetic characteristics of $\mathrm{CAM}^{[1]}$. CAM photosynthetic pathway is an effective means to optimize water use, carbon balance, and photon quantum efficiency of higher plants under environmental stresses ${ }^{[2]}$. The physiological and biochemical processes of CAM photosynthetic pathway are usually divided into four phases according to the $24 \mathrm{~h}$ light/dark cycle ${ }^{[3]}$. Phase $\mathrm{I}$ is the storage of malic acid after $\mathrm{CO}_{2}$ absorption at night or dark period. Phase III is the decarboxylation of stored malic acid during daytime or light period, and the process of carbon assimilation using photon quantum. At this time, high intracellular $\mathrm{CO}_{2}$ partial pressure causes stomatal closure. Phases II and IV are transitions between phase I and $\mathrm{III}^{[4]}$. The C3 photosynthetic pathway does not require malic acid to be loaded into vacuoles by active transport in dark period. Therefore, fixing $\mathrm{CO}_{2}$ through $\mathrm{C} 3$ pathway saves about $10 \%$ of the metabolic cost compared with CAM pathway ${ }^{[5]}$.

CAM and C3 pathways of CAM plant Kalanchoe blossfeldiana

\section{Received date: 2019-03-08 Accepted date: 2019-07-05}

Biographies: Yongsan Cheng, $\mathrm{PhD}$ candidate, research interests: plant environmental physiology. Email: 348522460@qq.com; Jie He, PhD, Associate Professor, research interests: plant photosynthetic physiology, Email: jie.he@ nie.edu.sg; Genhua Niu, PhD, Professor, research interests: plant environmental physiology. Email: genhua.niu@ag.tamu.edu; Fang Ji, PhD, Lecturer, research interest: plant environmental physiology, Email: jifang@ cau.edu.cn.

*Corresponding author: Dongxian He, Professor, research interests: plant environmental physiology and plant factory technology. Key Lab. of Agricultural Engineering in Structure and Environment, Ministry of Agriculture and Rural Affairs, China Agricultural University, Beijing 100083, China. Tel/Fax:+86-10-62737550, Email: hedx@cau.edu.cn. can be induced by short light period and long dark period, and plant pigments are involved in these processes ${ }^{[6-8]}$. Studies on $D$. ekapol showed that short light period increases net $\mathrm{CO}_{2}$ absorption in dark period, while long light period increases net $\mathrm{CO}_{2}$ absorption at early and end of light period ${ }^{[9]}$. The photosynthetic pathway and $\mathrm{CO}_{2}$ uptake of Doritaenopsis Queen Beer "Mantefon" can also be affected by light/dark cycle ${ }^{[10]}$. D. officinale as a facultative CAM plant usually has a photosynthetic pathway of coexistence of $\mathrm{C} 3$ and CAM under natural conditions ${ }^{[1,11]}$. Its photosynthetic pathway can be induced into an obligate $\mathrm{C} 3$ pathway in $4 \mathrm{~h} / 4 \mathrm{~h}$ short light/dark cycle, and its daily net $\mathrm{CO}_{2}$ exchange amount increases compared with in $12 \mathrm{~h} / 12 \mathrm{~h}$ light/dark cycle ${ }^{[11,12]}$. However, it deserves further study whether short light/dark cycles can significantly promote the growth and development of $D$. officinale in a long-term cultivation.

Artificial cultivation of $D$. officinale is mainly imitating wild cultivation and substrate cultivation in shaded greenhouses. As an advanced soilless cultivation technique, aeroponic cultivation has been applied to many horticultural crops including lettuce, tomato, cucumber, chrysanthemum, and poinsettia ${ }^{[13-16]}$. Compared with substrate cultivation, aeroponic cultivation can significantly increase the growth rate and soluble polysaccharide content of $D$. officinale $^{[17,18]}$. Therefore, the aim of this study was to investigate the effects of short light/dark cycles on photosynthetic pathway switching and growth as well as soluble polysaccharides accumulation of $D$. officinale in aeroponic cultivation.

\section{Materials and methods}

\subsection{Experimental materials and cultivation conditions}

The high buds of $D$. officinale were domesticated and cultivated in the plant factory laboratory of China Agricultural University in Beijing for 2 years before using as experimental materials. Two hundred $D$. officinale seedlings with uniform size 
were selected. The base of stem was clamped with sponge and planted in a cultivation tank $(1200 \mathrm{~mm} \times 900 \mathrm{~mm} \times 120 \mathrm{~mm})$. There were 117 holes in the cultivation panel. One seedling was planted in each hole. Nutrient solution was sprayed to the roots one time per hour and 10 seconds for each time. The formula of nutrient solution for aeroponic cultivation was followed by Cheng et al. ${ }^{[12]} \mathrm{EC}$ and $\mathrm{pH}$ of the nutrient solution were controlled at $0.6-0.7 \mathrm{~ms} / \mathrm{cm}$ and $6.0-6.5$, respectively.

The environmental conditions of the plant factory laboratory were controlled as follows. Artificial light source was LED lamp with red to blue light ration of 1.2 (WR-LED-16W, Beijing Lighting Valley Technology Co., Ltd., China). Photosynthetic photon flux density (PPFD) at the plant canopy was about $150 \mu \mathrm{mol} / \mathrm{m}^{2} \cdot \mathrm{s}$. Temperatures during the light and dark periods were $26^{\circ} \mathrm{C} \pm 1{ }^{\circ} \mathrm{C}$ and $22^{\circ} \mathrm{C} \pm 1{ }^{\circ} \mathrm{C}$, respectively. Relative humidity was $65 \% \pm 5 \%$ and mean of $\mathrm{CO}_{2}$ concentration was $670 \pm 30 \mu \mathrm{mol} / \mathrm{mol}$.

\subsection{Treatment design}

Three light/dark cycles were set up in $12 \mathrm{~h} / 12 \mathrm{~h}, 4 \mathrm{~h} / 4 \mathrm{~h}$, and $2 \mathrm{~h} / 2 \mathrm{~h}$, respectively. There were 20 seedlings of $D$. officinale in each light/dark cycle treatment. After $150 \mathrm{~d}$ of treatment, chlorophyll fluorescence parameters, net $\mathrm{CO}_{2}$ exchange characteristics, plant morphological characteristics, biomass, and soluble polysaccharide content of $D$. officinale were measured under $12 \mathrm{~h} / 12 \mathrm{~h}, 4 \mathrm{~h} / 4 \mathrm{~h}$, and $2 \mathrm{~h} / 2 \mathrm{~h}$ light/dark cycles, respectively.

\subsection{Measurement indexes and methods}

2.3.1 Chlorophyll fluorescence measurement of $D$. officinale leaves

A multi-function plant efficiency analyzer (M-PEA, Hansatech Inc., UK) was used to measure the O-J-I-P transients of the third fully expanded leaves from top of healthy plants. Maximum quantum yield for primary photochemistry $(\mathrm{Fv} / \mathrm{Fm})$, performance index $\left(\mathrm{PI}_{\mathrm{ABS}}\right)$ based on absorption energy, energy absorbed by active PS II reaction center $(\mathrm{ABS} / \mathrm{RC})$, and the open degree of active reaction center $\left(\psi_{o}\right)$ at $2 \mathrm{~ms}$ were obtained by OJIP-Test. The measuring light intensity was set to $5000 \mu \mathrm{mol} / \mathrm{m}^{2} \cdot \mathrm{s}$, the illumination time is set to $2 \mathrm{~s}$, and the light quality is $100 \%$ of the saturated pulsed red light. Following were the measurement times for the different dark/light cycle treatments: 1:00, 3:00, 5:00, 7:00, 21:00 for $12 \mathrm{~h} / 12 \mathrm{~h} ; 5: 00,7: 00,13: 00,15: 00,21: 00,23: 00$ for $4 \mathrm{~h} / 4 \mathrm{~h}$; and 3:00, 7:00, 11:00, 15:00, 19:00, 23:00 for $2 \mathrm{~h} / 2 \mathrm{~h}$. Six plants were measured at each time in each light/dark cycle treatment.

\subsubsection{Continuous measurement of net $\mathrm{CO}_{2}$ exchange rate}

The photosynthetic continuous measurement system ${ }^{[11]}$ used in this study consists of four cuvettes (L25 cm $\times W 15 \mathrm{~cm} \times \mathrm{H} 6 \mathrm{~cm}$ ), a host computer, and an IRGA $\mathrm{CO}_{2}$ analyzer (LI-7000, LICOR, Lincoln, USA). Before the measurement, pure $\mathrm{N}_{2}$ gas and $\mathrm{CO}_{2}$ standard gas with the concentration of $600 \mu \mathrm{mol} / \mathrm{mol}$ were used to calibrate the infrared ray gas analyzer (IRGA). Then the functional leaves of living plant samples were clamped into the leaf chamber, and the leaves were kept flat, then the leaf chamber was fastened.

The inlet air source of the leaf chamber was the air outside the plant factory laboratory (the average $\mathrm{CO}_{2}$ concentration was $370 \mu \mathrm{mol} / \mathrm{mol}$ ). The volume of buffer bottle was $20 \mathrm{~L}$ and the inlet air flow rate of the leaf chamber was $1 \mathrm{~L} / \mathrm{min}$. The temperature tracking mode was used to ensure that the temperature of the leaf chamber and was consistent in the plant factory laboratory. The $\mathrm{CO}_{2}$ concentration difference of reference air and samples of each leaf chamber were recorded once every $10 \mathrm{~min}$.
The leaf area of each leaf chamber was measured by referring to Yang et al. ${ }^{[19]}$ Then the net exchange rate of $\mathrm{CO}_{2}$ was calculated according to the difference of $\mathrm{CO}_{2}$ concentration between reference gas and sample gas and leaf area. The measurement method was referred to Zhang et al. ${ }^{[11]}$ Dark net $\mathrm{CO}_{2}$ exchange amount, light net $\mathrm{CO}_{2}$ exchange amount, and daily net $\mathrm{CO}_{2}$ exchange amount were calculated by integral method. Dark net $\mathrm{CO}_{2}$ exchange percentage $=$ dark net $\mathrm{CO}_{2}$ exchange amount $/$ daily net $\mathrm{CO}_{2}$ exchange amount $\times 100 \%$. Three replicates were conducted in this measurement for each light/dark cycle.

2.3.3 Measurement of plant morphological characteristics and biomass

The morphological indexes measured included the increases of plant height, internodes number, stem diameter, leaf area, leaf number, and leaf thickness. In order to calculate the increases of parameters above, the measurements were conducted at the beginning of the experiment and after $150 \mathrm{~d}$, respectively. Plant leaf area was calculated by the ratio of leaf image obtained by scanner to the black square of $1 \mathrm{~cm}^{2}$. The number of leaves was determined by the number of fully unfolded leaves. The blade thickness was obtained by measuring the transverse section of the blade with an optical microscope (BX51, Olympus Co., Japan). The plant height was measured from the connection of stem and root to growing point. The length of internodes longer than $0.5 \mathrm{~cm}$ was counted. The biomass indexes measured included total, stem, leaf, and root dry and fresh weight increases. Six plants were measured for each light/dark cycle treatment.

2.3.4 Measurement of soluble polysaccharide content

After $150 \mathrm{~d}$, the stems of $D$. officinale were dried in an oven at $50^{\circ} \mathrm{C}$, then crushed and screened by 40 meshes. The soluble polysaccharides content of $D$. officinale was measured by phenol-sulfuric acid method referenced by Li and Hirata ${ }^{[20]}$. Six plants were measured for each light/dark cycle.

\subsection{Statistical analysis}

SPSS 21 (IBM, Inc., Armonk, NY, USA) was used for statistical analysis. The variance analysis of the data was performed by Duncan method at the 0.05 significance level. Univariate analysis of variance (ANOVA) was used to test the difference of data mean.

\section{Results and discussion}

3.1 Effects of short light/dark cycles on photosynthetic electron transfer characteristics and photosynthetic pathway switching of $D$. officinale leaves

The $F_{v} / F_{m}$ of all leaves grown in different light/dark cycles could recover to above 0.8 in dark period (Table 1), indicating that the photosynthetic organs of leaves were not damaged significantly ${ }^{[21]}$. The $\mathrm{PI}_{\mathrm{ABS}}$ of $D$. officinale leaves under $2 \mathrm{~h} / 2 \mathrm{~h}$ cycle was higher than that under $4 \mathrm{~h} / 4 \mathrm{~h}$ light/dark cycle and much higher than that under $12 \mathrm{~h} / 12 \mathrm{~h} . \mathrm{PI}_{\mathrm{ABS}}$ is a more sensitive indicator than $\mathrm{F}_{\mathrm{v}} / \mathrm{F}_{\mathrm{m}}$. $\quad \mathrm{PI}_{\mathrm{ABS}}$ synthesized a single multi-parameter expression through three main functional steps of photosynthetic activity (light energy absorption, excitation energy capture and excitation energy conversion to electron transfer) through the PSII reaction center complex ${ }^{[22,23]}$. With the shortening of light/dark cycle, $\mathrm{PI}_{\mathrm{ABS}}$ increased gradually, which might be related to the increase of open degree of active reaction center $\left(\psi_{o}\right)$ at $2 \mathrm{~ms}$. There was no significant difference in the light energy absorbed by each active PS II reaction center (ABS/RC) in D. officinale leaves under different light/dark cycles. 
Table 1 Leaf chlorophyll fluorescence parameters of $D$. officinale under different short light/dark cycles

\begin{tabular}{ccccc}
\hline $\begin{array}{c}\text { Light/dark } \\
\text { cycle }\end{array}$ & Fv/Fm & $\mathrm{PI}_{\mathrm{ABS}}$ & $\mathrm{ABS} / \mathrm{RC}$ & $\psi_{\mathrm{o}}$ \\
\hline $12 \mathrm{~h} / 12 \mathrm{~h}$ & $0.82 \pm 0.01 \mathrm{NS}$ & $4.38 \pm 0.68 \mathrm{c}$ & $1.30 \pm 0.07 \mathrm{NS}$ & $0.57 \pm 0.05 \mathrm{~b}$ \\
$4 \mathrm{~h} / 4 \mathrm{~h}$ & $0.82 \pm 0.01 \mathrm{NS}$ & $5.41 \pm 0.57 \mathrm{~b}$ & $1.21 \pm 0.10 \mathrm{NS}$ & $0.58 \pm 0.05 \mathrm{~b}$ \\
$2 \mathrm{~h} / 2 \mathrm{~h}$ & $0.82 \pm 0.01 \mathrm{NS}$ & $7.51 \pm 0.57 \mathrm{a}$ & $1.22 \pm 0.05 \mathrm{NS}$ & $0.66 \pm 0.02 \mathrm{a}$ \\
\hline
\end{tabular}

Net $\mathrm{CO}_{2}$ exchange rate of $D$. officinale showed a multi-phase change of CAM pathway when the light/dark cycle was $12 \mathrm{~h} / 12 \mathrm{~h}$. When the light/dark cycle was shortened to $4 \mathrm{~h} / 4 \mathrm{~h}$ or $2 \mathrm{~h} / 2 \mathrm{~h}$, net $\mathrm{CO}_{2}$ exchange rate of $D$. officinale showed a $\mathrm{C} 3$ pathway pattern, i.e. net absorption of $\mathrm{CO}_{2}$ in light period and net release of $\mathrm{CO}_{2}$ in dark period (Figure 1). The result is consistent with that of Zhang et al. ${ }^{[1]}$

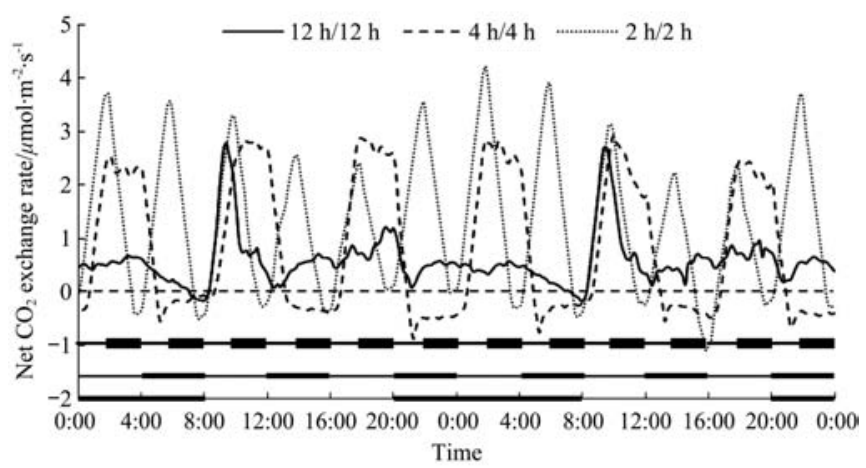

Note: The thin black line on the horizontal axis indicates light period, and the thick black line indicates dark period.

Figure 1 Net $\mathrm{CO}_{2}$ exchange rate of $D$. officinale under different light/dark cycles

Contrary to $12 \mathrm{~h} / 12 \mathrm{~h} \mathrm{light/dark} \mathrm{cycle,} \mathrm{dark} \mathrm{net} \mathrm{CO}_{2}$ exchange amount and dark net $\mathrm{CO}_{2}$ exchange percentage of $D$. officinale in short light/dark cycles of $4 \mathrm{~h} / 4 \mathrm{~h}$ and $2 \mathrm{~h} / 2 \mathrm{~h}$ were negative, and light net $\mathrm{CO}_{2}$ exchange amount and daily net $\mathrm{CO}_{2}$ exchange amount were higher (Table 2). This indicated that photosynthetic pathway of $D$. officinale could be switched to $\mathrm{C} 3$ by the short light/dark cycles. The higher daily net $\mathrm{CO}_{2}$ exchange amounts during short light/dark cycles were mainly due to the higher light net $\mathrm{CO}_{2}$ exchange amounts. The higher light net $\mathrm{CO}_{2}$ exchange amounts during short light/dark cycles might be related to stomatal movement, leaf thickness, and leaf anatomical structure. This was due to the fact that the short light/dark cycles could induce the higher stomatal conductances of $D$. officinale in light period ${ }^{[12]}$. Structure features of leaf might affect $\mathrm{CO}_{2}$ concentration in chloroplast stroma ${ }^{[24]}$, thus affecting the photosynthetic capacity of D. officinale. Whatever it was, the photosynthetic pathway of $D$. officinale could be switched to $\mathrm{C} 3$ pathway, and the daily net $\mathrm{CO}_{2}$ exchange amount could be increased by the short light/dark cycles.

Table 2 Net $\mathrm{CO}_{2}$ exchange characteristics of $D$. offficinale under different light/dark cycles

\begin{tabular}{ccccc}
\hline $\begin{array}{c}\text { Light/ } \\
\text { dark cycle }\end{array}$ & $\begin{array}{c}\text { Light net } \mathrm{CO}_{2} \\
\text { exchange } \\
\text { amount } \\
/ \mathrm{mmol} \cdot \mathrm{m}^{-2} \cdot \mathrm{d}^{-1}\end{array}$ & $\begin{array}{c}\text { Dark net } \mathrm{CO}_{2} \\
\text { exchange } \\
\text { amount } \\
/ \mathrm{mmol}^{-2} \cdot \mathrm{d}^{-1}\end{array}$ & $\begin{array}{c}\text { Daily net } \mathrm{CO}_{2} \\
\text { exchange } \\
\text { amount } \\
/ \mathrm{mmol} \cdot \mathrm{m}^{-2} \cdot \mathrm{d}^{-1}\end{array}$ & $\begin{array}{c}\text { Dark net } \mathrm{CO}_{2} \\
\text { exchange } \\
\text { percentage } \\
/ \%\end{array}$ \\
\hline $12 \mathrm{~h} / 12 \mathrm{~h}$ & $50.5 \pm 2.1 \mathrm{~b}$ & $9.2 \pm 1.6 \mathrm{a}$ & $59.7 \pm 0.4 \mathrm{~b}$ & $15.4 \pm 2.8 \mathrm{a}$ \\
$4 \mathrm{~h} / 4 \mathrm{~h}$ & $87.9 \pm 5.4 \mathrm{a}$ & $-11.8 \pm 1.0 \mathrm{~b}$ & $76.1 \pm 6.4 \mathrm{a}$ & $-15.6 \pm 2.6 \mathrm{~b}$ \\
$2 \mathrm{~h} / 2 \mathrm{~h}$ & $96.6 \pm 5.5 \mathrm{a}$ & $-13.5 \pm 3.9 \mathrm{~b}$ & $83.1 \pm 1.6 \mathrm{a}$ & $-16.1 \pm 4.3 \mathrm{~b}$ \\
\hline
\end{tabular}

3.2 Effects of short light/dark cycles on morphogenesis of $D$. officinale

After $150 \mathrm{~d}$, the plant heights of $D$. officinale treated with $4 \mathrm{~h} / 4 \mathrm{~h}$ and $2 \mathrm{~h} / 2 \mathrm{~h}$ short light/dark cycles were significantly higher than that treated with $12 \mathrm{~h} / 12 \mathrm{~h}$ light/dark cycle. The colors of stem and leaf were obviously red under $2 \mathrm{~h} / 2 \mathrm{~h}$ shorter light/dark cycle (Figure 2). Compared with $12 \mathrm{~h} / 12 \mathrm{~h}$ light/dark cycle, $D$. officinale plants treated with $4 \mathrm{~h} / 4 \mathrm{~h}$ and $2 \mathrm{~h} / 2 \mathrm{~h}$ short light/dark cycles had thinner and more leaves, larger leaf area, more internodes, larger plant height, and thicker stems (Table 3).
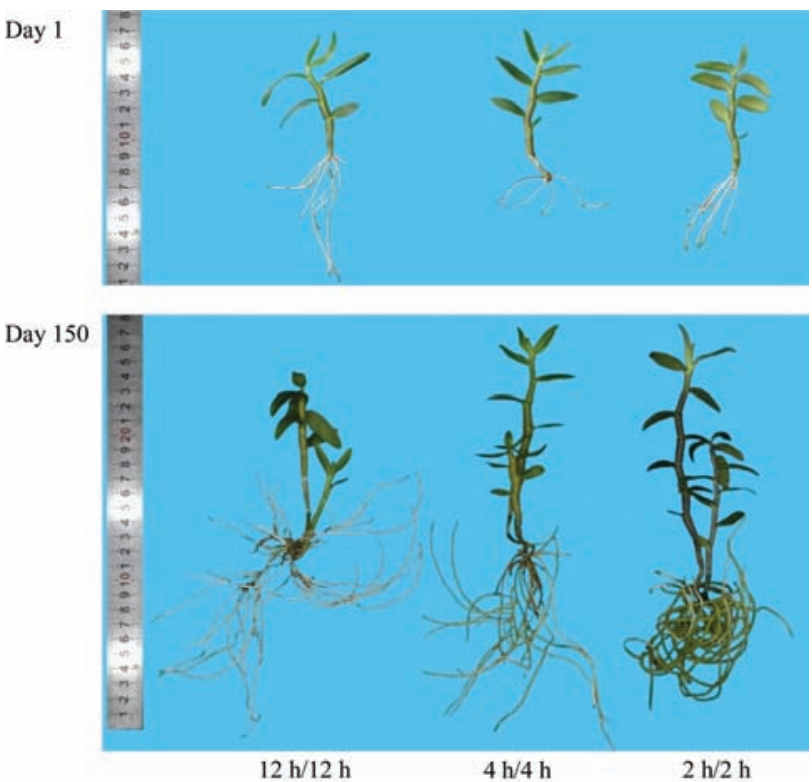

Figure 2 Morphological pictures of D. officinale under different light/dark cycles

Table 3 Morphological characteristics of $D$. officinale under different light/dark cycles

\begin{tabular}{ccccccc}
\hline $\begin{array}{c}\text { Light/dark } \\
\text { cycle }\end{array}$ & $\begin{array}{c}\text { Plant height } \\
\text { increase } \\
/ \mathrm{cm}\end{array}$ & $\begin{array}{c}\text { Increase of } \\
\text { internodes } \\
\text { number }\end{array}$ & $\begin{array}{c}\text { Stem } \\
\text { diameter } \\
/ \mathrm{mm}\end{array}$ & $\begin{array}{c}\text { Leaf area } \\
\text { increase } \\
/ \mathrm{cm}^{2}\end{array}$ & $\begin{array}{c}\text { Leaf } \\
\text { number } \\
\text { increase }\end{array}$ & $\begin{array}{c}\text { Leaf } \\
\text { thickness } \\
/ \mathrm{mm}\end{array}$ \\
\hline $12 \mathrm{~h} / 12 \mathrm{~h}$ & $10.2 \pm 0.5 \mathrm{~b}$ & $8.0 \pm 1.4 \mathrm{~b}$ & $5.3 \pm 0.8 \mathrm{~b}$ & $4.7 \pm 2.1 \mathrm{~b}$ & $3.3 \pm 0.6 \mathrm{~b}$ & $0.43 \pm 0.01 \mathrm{a}$ \\
$4 \mathrm{~h} / 4 \mathrm{~h}$ & $19.4 \pm 4.4 \mathrm{a}$ & $16.0 \pm 3.6 \mathrm{a}$ & $6.2 \pm 0.3 \mathrm{a}$ & $15.2 \pm 4.4 \mathrm{a}$ & $6.3 \pm 0.6 \mathrm{a} 0.41 \pm 0.01 \mathrm{~b}$ \\
$2 \mathrm{~h} / 2 \mathrm{~h}$ & $15.7 \pm 1.4 \mathrm{a}$ & $10.5 \pm 1.3 \mathrm{~b}$ & $5.7 \pm 0.3 \mathrm{ab}$ & $16.5 \pm 3.4 \mathrm{a} \quad 6.5 \pm 0.6 \mathrm{a} 0.41 \pm 0.01 \mathrm{~b}$
\end{tabular}

Anthocyanins were accumulated on the back of the leaves of $D$. officinale under $2 \mathrm{~h} / 2 \mathrm{~h}$ shorter light/dark cycle, but not with plants under $12 \mathrm{~h} / 12 \mathrm{~h}$ and $4 \mathrm{~h} / 4 \mathrm{~h}$ light/dark cycles (Figure 3). The biosynthesis of anthocyanins was related to cryptochrome as a blue light receptor ${ }^{[25]}$. The light-activated cryptochrome could remain in the dark for a period of time ${ }^{[26]}$, which might be the reason for the high accumulation of anthocyanins in D. officinale treated with $2 \mathrm{~h} / 2 \mathrm{~h}$ shorter light/dark cycle.

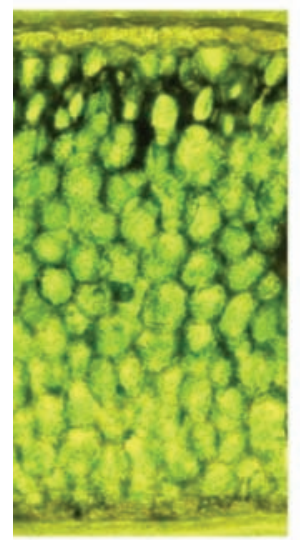

$12 \mathrm{~h} / 12 \mathrm{~h}$

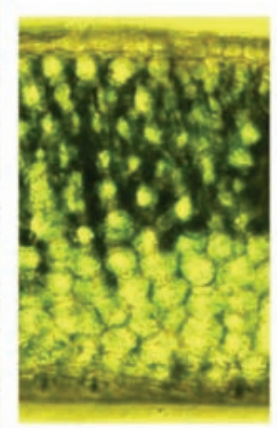

$4 \mathrm{~h} / 4 \mathrm{~h}$

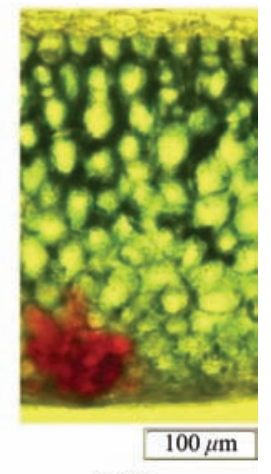

$2 \mathrm{~h} / 2 \mathrm{~h}$
Figure 3 Leaf cross sectional anatomies of $D$. officinale under different light/dark cycles 
3.3 Effects of short light/dark cycles on biomass and soluble polysaccharide accumulations of $D$. officinale

The increases of total fresh weight, total dry weight, stem fresh weight, stem dry weight, leaf fresh weight, leaf dry weight, and root fresh weight of $D$. officinale treated with short light/dark cycles of $4 \mathrm{~h} / 4 \mathrm{~h}$ and $2 \mathrm{~h} / 2 \mathrm{~h}$ were significantly higher than those treated with $12 \mathrm{~h} / 12 \mathrm{~h}$ light/dark cycle. The increase of root dry
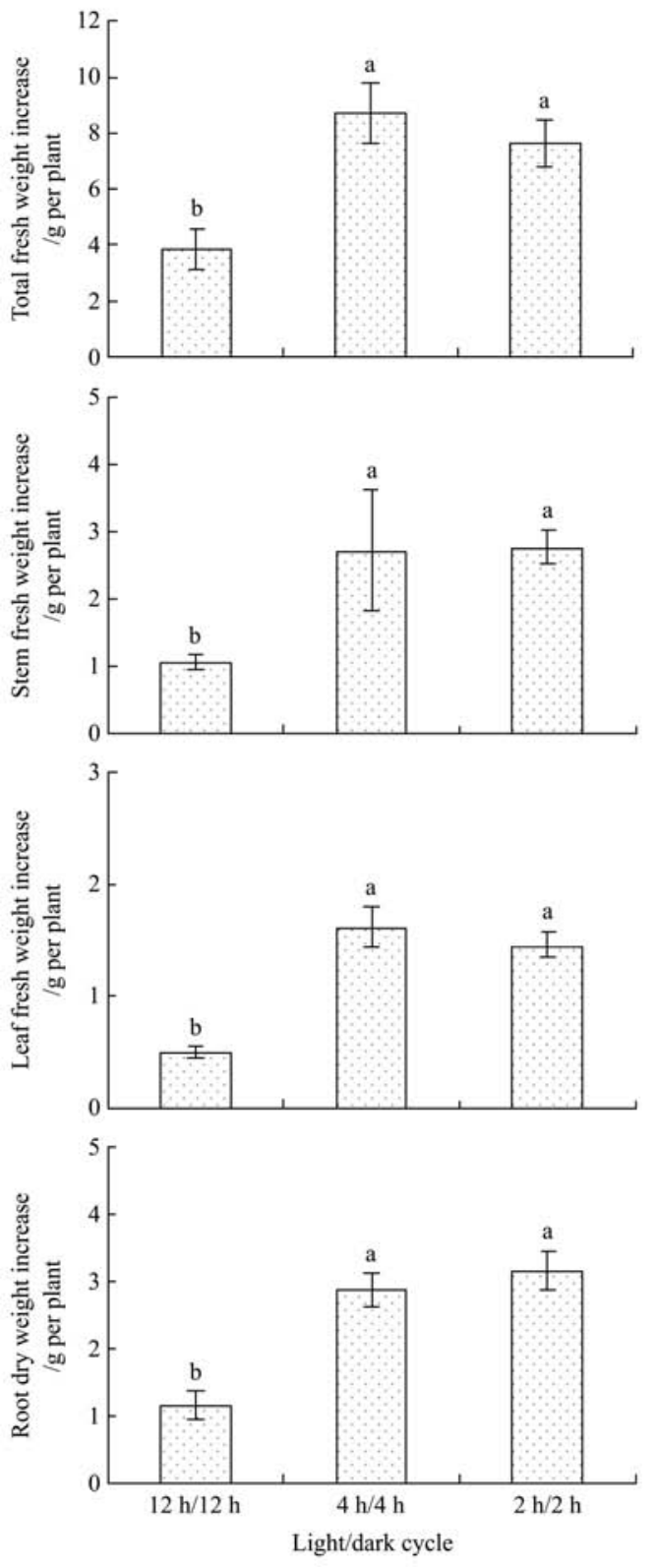

Note: Different growth parameters were recorded at day 1 and day 150 , respectively. Different letters indicate statistically significant differences by Duncan's multiple range test $(p<0.05)$.

Figure 4 Biomass accumulation of $D$. officinale under different short light/dark cycles

Compared with $12 \mathrm{~h} / 12 \mathrm{~h}$ light/dark cycle, the soluble polysaccharides content of $D$. officinale treated with $4 \mathrm{~h} / 4 \mathrm{~h}$ short light/dark cycle decreased significantly. When the light/dark cycle was shortened to $2 \mathrm{~h} / 2 \mathrm{~h}$, the soluble polysaccharides content increased to the level of $12 \mathrm{~h} / 12 \mathrm{~h}$ light/dark cycle (Figure 5). The soluble polysaccharides yield of $D$. officinale treated with $2 \mathrm{~h} / 2 \mathrm{~h}$ shorter light/dark cycle was significantly higher than that treated with $12 \mathrm{~h} / 12 \mathrm{~h}$ and $4 \mathrm{~h} / 4 \mathrm{~h}$ light/dark cycles. Studies had shown that light intensity and light quality affected the accumulation of soluble polysaccharides in $D$. officinale, while the accumulation of soluble polysaccharides was positively correlated with weight in $2 \mathrm{~h} / 2 \mathrm{~h}$ shorter light/dark cycle was significantly higher than that in $12 \mathrm{~h} / 12 \mathrm{~h}$ and $4 \mathrm{~h} / 4 \mathrm{~h}$ light/dark cycles (Figure 4). The effects of short light/dark cycles of $4 \mathrm{~h} / 4 \mathrm{~h}$ and $2 \mathrm{~h} / 2 \mathrm{~h}$ on the long-term biomass accumulation of $D$. officinale were consistent with their effects on the short-term daily net $\mathrm{CO}_{2}$ exchange amount of D. officinale.
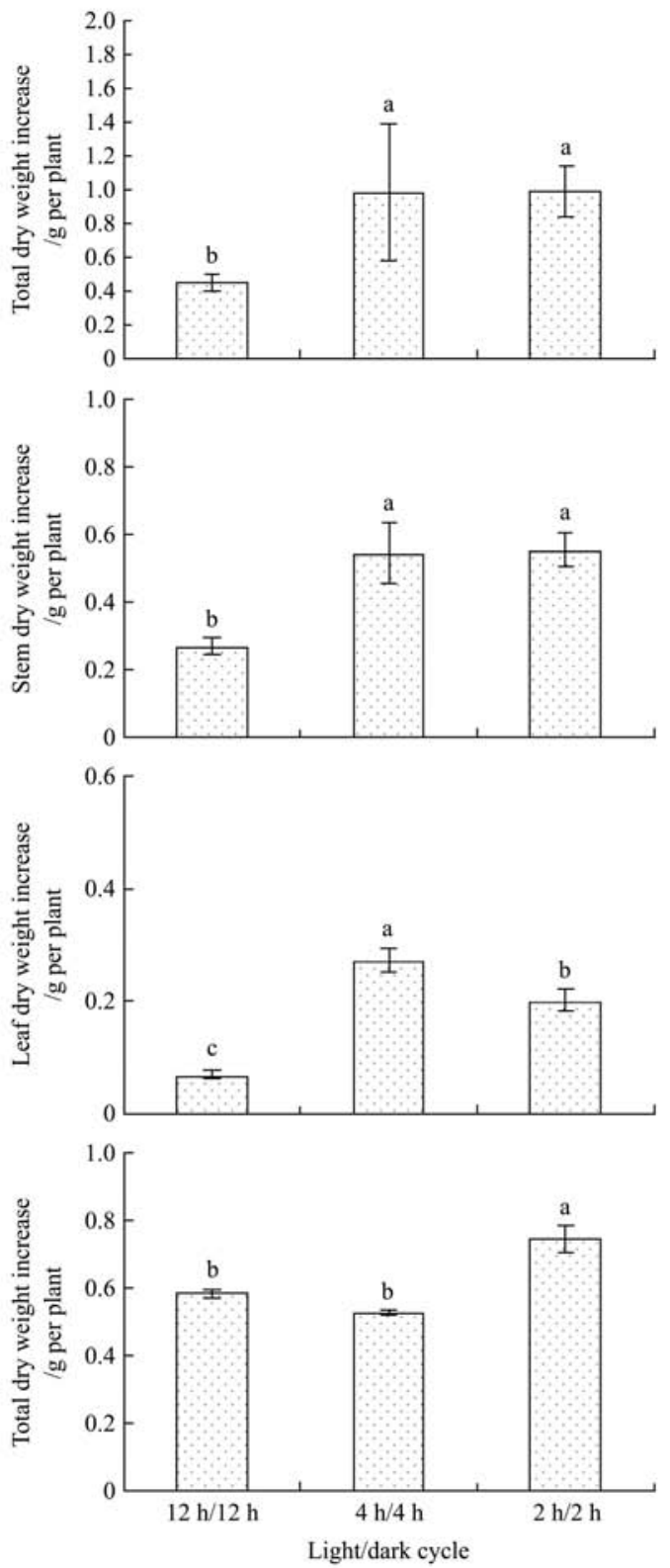

environmental stresses ${ }^{[27,28]}$. The soluble polysaccharides content of $D$. officinale treated with $2 \mathrm{~h} / 2 \mathrm{~h}$ shorter light/dark cycle was significantly higher than that treated with $4 \mathrm{~h} / 4 \mathrm{~h}$ and $12 \mathrm{~h} / 12 \mathrm{~h}$ short light/dark cycles, which might be related to the responses of plants to a sudden induction of light environment stress. Soluble polysaccharides play a role by plants in protecting plants from abiotic stresses ${ }^{[29]}$. The accumulation of anthocyanins also proved that the shorter light/dark cycle of $2 \mathrm{~h} / 2 \mathrm{~h}$ might cause some photopreoction of $D$. officinale against a sudden change of light. The results of Lin and $\mathrm{Lai}^{[28]}$ also showed that the soluble sugar polysaccharide content in $D$. officinale was positively correlated 
with the activity of PEPC, while the expression of CAM photosynthetic pathway was closely correlated with the activity of $\mathrm{PEPC}^{[30]}$. It explained why the soluble polysaccharides content in D. officinale treated with $4 \mathrm{~h} / 4 \mathrm{~h}$ short light/dark cycle was

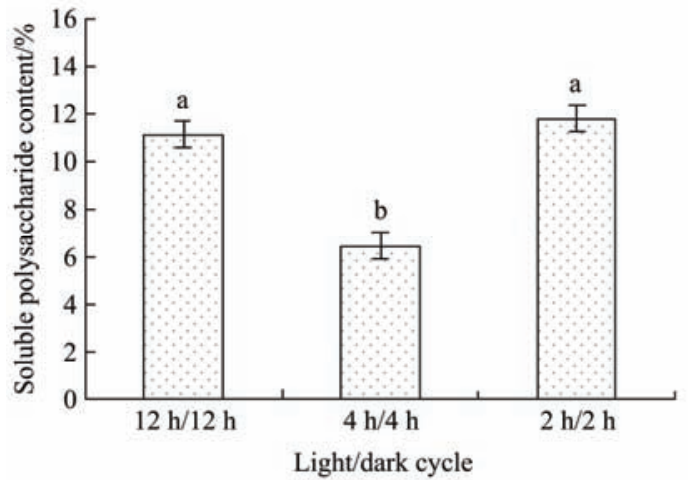

significantly lower than that treated with $12 \mathrm{~h} / 12 \mathrm{~h}$ light/dark cycle. While it could not explain why the $D$. officinale treated with a $2 \mathrm{~h} / 2 \mathrm{~h}$ light/dark cycle had higher soluble polysaccharides content than that treated with $12 \mathrm{~h} / 12 \mathrm{~h}$ light/dark cycle.

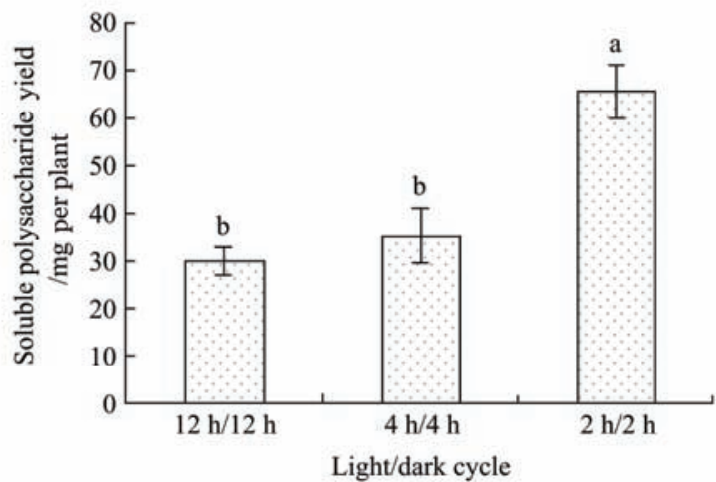

Note: \% represents g per $100 \mathrm{~g}$. Different letters indicate statistically significant differences by Duncan's multiple range test $(p<0.05)$.

Figure 5 Soluble polysaccharides content and yield of $D$. officinale under different short light/dark cycles

\section{Conclusions}

Based on photosynthetic electron transfer characteristics, photosynthetic pathways, biomass and soluble polysaccharides accumulation of $D$. officinale plants grown aeroponically under three light/dark cycles for $150 \mathrm{~d}$, we concluded that photosynthetic efficiency of $D$. officinale under $4 \mathrm{~h} / 4 \mathrm{~h}$ and $2 \mathrm{~h} / 2 \mathrm{~h}$ short light/dark cycles was better than that under $12 \mathrm{~h} / 12 \mathrm{~h}$ light/dark cycle because of the photosynthetic pathway switching from CAM to C3. The results also demonstrated that under $4 \mathrm{~h} / 4 \mathrm{~h}$ and $2 \mathrm{~h} / 2 \mathrm{~h}$ short light/dark cycles, $D$. officinale plants had great increases in daily net $\mathrm{CO}_{2}$ exchange amount, and fresh/dry weights compared with those in $12 \mathrm{~h} / 12 \mathrm{~h}$ light/dark cycle. The soluble polysaccharides yield of $D$. officinale in the $2 \mathrm{~h} / 2 \mathrm{~h}$ light/dark cycle was higher than that in $12 \mathrm{~h} / 12 \mathrm{~h}$ light/dark cycle. Therefore, shorter light/dark cycles of $2 \mathrm{~h} / 2 \mathrm{~h}$ is recommended for light environment adjustment of $D$. officinale for achieving the growth and quality control by keep the higher soluble polysaccharides content and yield.

\section{Acknowledgements}

This work was supported by China Agriculture Research System (Grant No. CARS-21) and National Natural Science Foundation of China (Grant No. 31372089). Thanks to Mr. Guomin Zheng, Mr. Po Yang, and Mr. Aiguo Zhang for their technical supports.

This manuscript was presented at 2019 International Symposium on Environment Control Technology for Value-added Plant Production hold in Beijing at Aug. 27-30, 2019.

\section{[References]}

[1] Su W, Zhang G. The photosynthesis pathway in leaves of Dendrobium officinale. Acta Phytoecologica Sinica, 2003; 27(5): 631-637.

[2] Borland A M, Griffiths H, Broadmeadow M S J, Fordham M C, Maxwell C. Short-term changes in carbon-isotope discrimination in the C3-CAM intermediate Clusia minor L. growing in Trinidad. Oecologia, 1993; 95(3): 444-453.

[3] Osmond C B. Crassulacean acid metabolism - curiosity in context. Annual Review of Plant Physiology and Plant Molecular Biology, 1978; 29: 379-414.

[4] Cockburn W, Ting I P. Relationships between stomatal behavior and internal carbon dioxide concentration in crassulacean acid metabolism plants. Plant Physiology, 1979; 63(6): 1029-1032.

[5] Winter K, Smith J A C. Crassulacean acid metabolism: biochemistry, ecophysiology, and evolution. Berlin: Springer-Verlag, 1996; pp.406-416

[6] Gregory F G, Thimann K V. The interrelation between $\mathrm{CO}_{2}$ metabolism and photoperiodism in Kalanchoë. Plant Physiology, 1954; 29: 414.

[7] Queiroz O, Morel C. Photoperiodism and enzyme activity. Plant Physiolology, 1974; 4: 596-602.

[8] Wilkins M B. An endogenous rhythm in the rate of carbon dioxide output of Bryophyllum. IV. Effect of intensity of illumination on entrainment of the rhythm by cycles of light \& darkness. Plant Physiology, 1962; 37: 735-741.

[9] Sekizuka F, Nose A, Kavamitsu Y, Murayama S, Arisumi K I. Effects of day length on gas exchange characteristics in the crassulacean acid metabolism plant Dendrobium ekapol cv. Panda. Japanese Journal of Crop Science, 1995; 64: 201-208.

[10] Kim H J, Ju H L, Lee H B, An S K, Kim K S. CO $_{2}$ uptake behavior and vegetative growth of Doritaenopsis Queen Beer 'Mantefon' orchids as influenced by light/dark cycle manipulation. Flower Research Journal, 2017; 25: 253-261.

[11] Zhang Z, He D, Niu G, Gao R. Concomitant CAM and C3 photosynthetic pathways in Dendrobium officinale plants. Journal of the American Society for Horticultural Science, 2014; 139(3): 290-298.

[12] Cheng Y, He D, He J, Niu G, Gao R. Effect of light/dark cycle on photosynthetic pathway switching and $\mathrm{CO}_{2}$ absorption in two Dendrobium species. Frontiers in Plant Science, 2019; 10: 659. doi: 10.3389/fpls.2019.00659

[13] He J, Lee S K. Growth and photosynthetic responses of three aeroponically grown lettuce cultivars (Lactuca sativa L.) to different rootzone temperatures and growth irradiances under tropical aerial conditions. Journal of Pomology \& Horticultural Science, 2015; 73(2): 173-180.

[14] Biddinger E J, Liu C, Joly R J, Raghothama K G. Physiological and molecular responses of aeroponically grown tomato plants to phosphorus deficiency. Journal of the American Society for Horticultural Science, 1998; 123(2): 330-333.

[15] Molitor H D, Fischer M, Popadopoulos A P. Effect of several parameters on the growth of chrysanthemum stock plants in aeroponics. Acta Horticulturae, 1999; 481: 179-186.

[16] Scoggins H L, Mills H A. Poinsettia growth, tissue nutrient concentration, and nutrient uptake as influenced by nitrogen form and stage of growth. Journal of Plant Nutrition, 1998; 21(1): 191-198.

[17] Dai G. Aeroponic cultivation method of Dendrobium officinale. Chinese patent, CN102972269A, 2013-03-20. (in Chinese)

[18] Huang Q. A method of aeroponic cultivation of Dendrobium officinale. Chinese Patent, CN106376445A, 2017-02-08. (in Chinese)

[19] Yang J, Chen C, Han X, Li X, Liebig H P. Measurement of vegetable leaf area using digital image processing techniques. Transactions of the CSAE, 2002; 18(4): 155-158

[20] Li M, Xu G, Hirata Y, Niwa M. Quantitative analysis of polysaccharides in Chinese Grug "Shihu” (Dendrobium). Chinese Herbal Medicines, 1990; 10: $10-12$.

[21] Bjorkman D, Demmnig B. Comparison of the effect of excessive light on 
chlorophyll florescence $(77 \mathrm{~K})$ and photon yield of $\mathrm{O}_{2}$ evolution in leaves of higher-plants. Planta, 1987; 171(2): 171-184.

[22] Appenroth K J, Stöckel J, Srivastava A, Strasser R J. Multiple effects of chromate on the photosynthetic apparatus of Spirodela polyrhiza as probed by OJIP chlorophyll a fluorescence measurements. Environmental Pollution, 2001; 115(1): 49-64.

[23] Van Heerden P D R, Strasser R J, Krüger G H J. Reduction of dark chilling stress in $\mathrm{N}_{2}$-fixing soybean by nitrate as indicated by chlorophyll a fluorescence kinetics. Physiologia Plantarum, 2004; 121: 239-249.

[24] Terashima I, Hanba Y T, Tholen D, Niinemets U. Leaf functional anatomy in relation to photosynthesis. Plant Physiology, 2001; 155: 108-116.

[25] Mancinelli A L, Rossi F, Moroni A. Chryptochrome, phytochrome, and anthocyanin production. Plant Physiology, 1991; 96: 1079-1085.

[26] Kurata H, Mochizuki A, Okuda N, Seki M, Furusaki S. Intermittent light irradiation with second- or hour-scale periods controls anthocyanin production by strawberry cells. Enzyme and Microbial Technology, 2000; 26: 621-629.

[27] Xu B, Cui Y, Guo C, Xia G. Dynamic variation of biomass and content of polysaccharide and alkaloid in protocorm like bodies from Dendrobium officinale at different light intensities and incubation time. Chinese Traditional and Herbal Drugs, 2012; 43(2): 355-359. (in Chinese)

[28] Lin X, Lai Z. Effects of light quality on expression of PEPC and polysaccharide accumulation in Dendrobium officinale. Chinese Journal of Tropical Crops, 2017; 5: 61-65. (in Chinese)

[29] Rolland F, Baena-Gonzalez E, Sheen J. Sugar sensing and signaling in plants: conserved and novel mechanisms. Annual Review of Plant Biology, 2006; 57: 675-709.

[30] Nimmo H G. The regulation of phosphoenolpyruvate carboxylase in CAM plants. Trends in Plant Science, 2000; 5(2): 75-80. 